\title{
Lumbar spine dimensions in paraparetic patients: a 10 year follow up study
}

\author{
A Catz MD,${ }^{1,4,5}$ I Reider-Grosswasser MD,${ }^{2.4}$ I Gutman MD ${ }^{1}$ R Gepstein MD $, 3,4$ \\ L Mendelson $\mathrm{MD}^{1,4}$ \\ ${ }^{1}$ Spinal Rehabilitation and Radiological Departments, Loewenstein Rehabilitation Hospital \\ 278 Achuza Street, PO Box 3, Ra'anana 43100; ${ }^{2}$ Neuro-Radiological Unit Ichilov \\ Hospital, Tel-Aviv Medical Center, Tel-Aviv; ${ }^{3}$ Orthopedic Department, Spinal Surgery \\ Unit, Meir Hospital, Kfar-Sava; ${ }^{4}$ Sackler Faculty of Medicine, Tel-Aviv University, \\ Tel-Aviv; ${ }^{5}$ IDF Medical Corps ${ }^{5}$ Israel.
}

Lumbar spinal AP radiographs of 13 C3-T11 paraparetic patients taken at about a 10 year interval were compared. The height $(\mathrm{H})$ and maximum width $(\mathrm{W})$ of the interapophysolaminar spaces (IALS), the width of the vertebral bodies at their waist (V) and the relationship between them showed minimal change over the follow up period. The difference between the late and early mean IALS height values increased caudally but was statistically significant only below L5. Subjective evaluation of the consecutive $x$-ray films revealed few new degenerative abnormalities. It is concluded that the normal aging process, which includes horizontal spreading of the lumbar vertebral bodies and narrowing of the lumbar spinal canal, is not accelerated by paraparesis and may even be retarded by relative immobilization.

Keywords: lumbar spine; spinal canal; interlaminoapophyseal space (IALS); aging; paraparesis.

\section{Introduction}

The dimensions of the lumbar spinal canal of normal subjects change with aging. ${ }^{1}$ Horizontal spreading of the lumbar vertebral bodies and hypertrophy of the posterior arches with narrowing of the vertebral canal occur through middle and old age. ${ }^{1-3}$ These processes, however, have not been evaluated following spinal cord lesions, to the best of our knowledge. Degenerative changes of the lumbar spine, which might contribute to narrowing of the spinal canal, have not been described in patients with a spinal cord lesion, despite the high frequency of such changes at various joints below the level of neurological deficit. ${ }^{4}$ In order to assess the effect of spinal cord damage on vertebral changes below the lesion, early and late (after 10 years) x-ray films of the lumbar spinal canal of patients with spinal cord lesions were compared. Results indicated that only few significant changes in the dimensions of the lumbar spinal canal occurred.

\section{Patients and methods}

Lumbar anteroposterior (AP) x-ray films were taken at about a 10 year interval in 13 paraparetic patients (12 males and 1 female). The patients had a mean age of 37.5 years (range $24-67$ years, $S D=16.2$ ) at the time of the first radiograph. In 9 patients the spinal lesion was traumatic. The remaining spinal pathologies included: tumour, arachnoid cyst and spinal stenosis. The levels of the lesions ranged from below $\mathrm{C} 3$ to below T11. Spasticity was found in 11 patients and reduced tone in 2 . Nine patients were confined to a wheelchair, and 4 were able to walk with aids (Table I).

The AP view of the lumbar spine was obtained from routine intravenous pyelography studies (Fig 1). The films were examined by a physician from the Department of Spinal Rehabilitation and by two independent radiologists. The radiographs were evaluated both qualitatively and quantitatively. The quantitative assessment included measurement of the lumbar canal 
Table I Patient data

\begin{tabular}{|c|c|c|c|c|c|}
\hline $\begin{array}{l}\text { Patient } \\
\text { number }\end{array}$ & $\operatorname{Age}^{*} / \operatorname{Sex}$ & $\begin{array}{l}\text { Etiology } \\
\text { of lesion }\end{array}$ & $\begin{array}{l}\text { Level } \\
\text { of lesion }\end{array}$ & Tonus & Mobility \\
\hline 1 & $27 / F$ & Trauma & C6 & ++ & Wheelchair \\
\hline 2 & $24 / \mathrm{M}$ & Trauma & $\mathrm{T} 8$ & ++ & Wheelchair \\
\hline 3 & $58 / \mathrm{M}$ & Trauma & $\mathrm{C} 4$ & ++ & Walking frame \\
\hline 4 & $24 / \mathrm{M}$ & Trauma & $\mathrm{C} 7$ & ++ & Wheelchair \\
\hline 5 & $57 / \mathrm{M}$ & Spinal stenosis & $\mathrm{C} 3$ & ++ & Walking stick \\
\hline 6 & $52 / \mathrm{M}$ & Tumour & $\mathrm{T} 7$ & ++ & $\begin{array}{c}\text { Walking frame }+ \\
\text { long leg braces }\end{array}$ \\
\hline 7 & $27 / \mathrm{M}$ & Trauma & $\mathrm{T} 2$ & ++ & $\begin{array}{l}\text { Crutches }+ \\
\text { long leg braces }\end{array}$ \\
\hline 8 & 28/M & Trauma & $\mathrm{C} 5$ & ++ & Wheelchair \\
\hline 9 & 26/M & Trauma & T6 & ++ & Wheelchair \\
\hline 10 & $24 / \mathrm{M}$ & Trauma & C5 & ++ & Electric wheelchair \\
\hline 11 & $24 / \mathrm{M}$ & Arachnoid cyst & $\mathrm{T} 4$ & ++ & Wheelchair \\
\hline 12 & $67 / \mathrm{M}$ & Trauma & T11 & -- & Wheelchair \\
\hline 13 & 49/M & Unknown & T10 & -- & Wheelchair \\
\hline
\end{tabular}

*Age at time of early radiograph.

$++=$ spastic

$--=$ flaccid

a

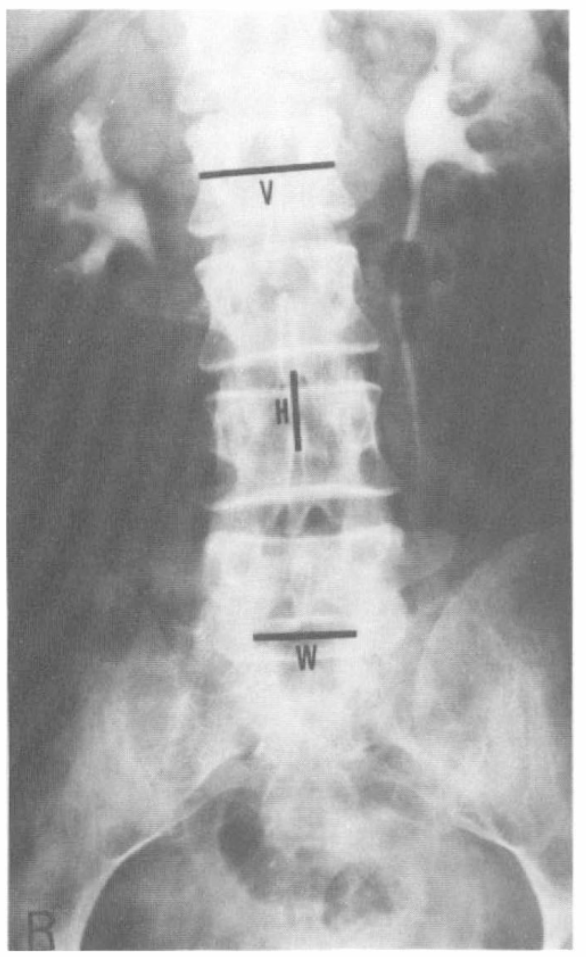

b

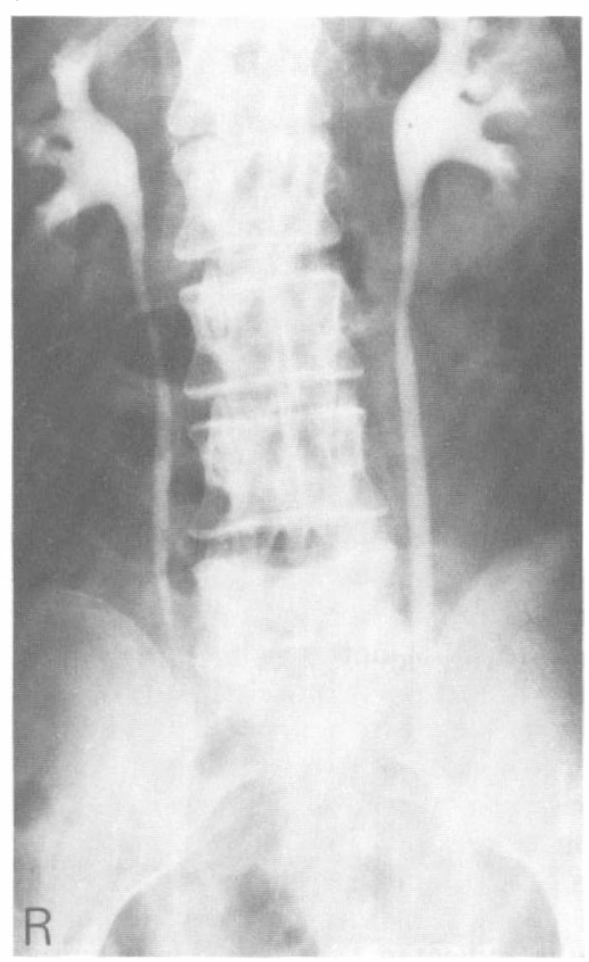

Figure 1 Lumbar spine on AP radiograph. (a) Early study. $\mathrm{H}=$ IALS height; $\mathrm{W}=$ maximal IALS width. (b) 10 year follow up. 
and vertebral bodies. The dimensions of the lumbar canal were evaluated according to measurements of the interapophysolaminar spaces (IALS). Vouge defined the IALS as the translucency between the laminae and the articular processes of 2 adjacent vertebrae, as seen on a plain radiograph of the lumbar spine. ${ }^{5}$ The IALS is usually triangular from L1 down to L5, and lozenge-shaped between the L5-S1 vertebrae. The apex of the triangle is notched by the projection of the spinous process of the overlying vertebra, and its lower angles are 'cut off' by the superior articular processes of the underlying vertebra. The maximum height $(\mathrm{H})$ and width (W) of each IALS and the width of the overlying vertebra at the waist (V) were measured on the films (about $0.5 \mathrm{~mm}$ accuracy).

The width index (IALS width/width of L3 vertebral body) (WI) and the ratio between the height and the width of the IALS $(\mathrm{H} / \mathrm{W})$ were calculated to obtain comparable data, thus avoiding the drawback of geometric enlargement. Vouge had chosen the width of the L3 vertebra as a reference, because this vertebra was best displayed on plain films. ${ }^{5}$

The differences between the late and early dimensions were assessed by the paired t-test.

\section{Results}

The width index (WI) and the height/width ratio $(\mathrm{H} / \mathrm{W})$ in the present patients (Table II) were similar to those found in normal subjects examined previously by Vouge. ${ }^{5}$

The width index (WI) as well as the mean IALS width (W), the width of the overlying vertebrae $(\mathrm{V})$ and the $\mathrm{W} / \mathrm{V}$ ratio (Table III,

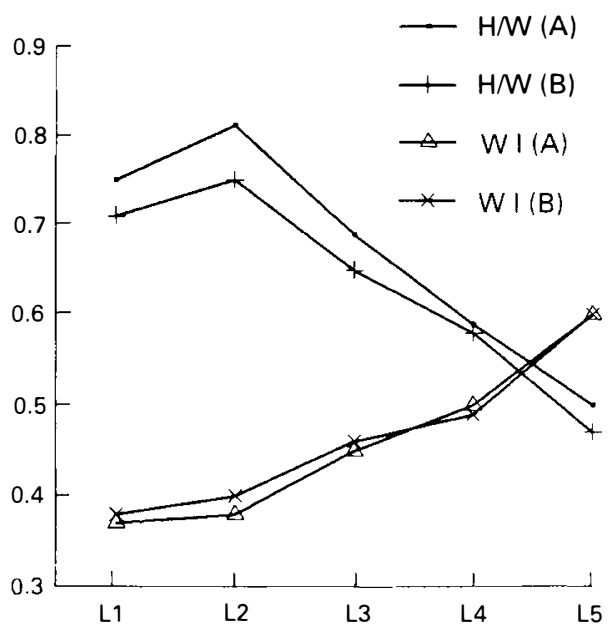

Figure 2 Width index (WI) and IALS heightwidth ratio $(\mathrm{H} / \mathrm{W})$ below the lumbar vertebrae. (A) Early radiograph. (B) Late radiograph.

Fig 2) increased from L1 to L5. The IALS height $(\mathrm{H})$, however, was about the same, and the mean values of the ratios $\mathrm{H} / \mathrm{W}$ and $\mathrm{H} / \mathrm{V}$ decreased from $\mathrm{L} 2$ down to L5 (Table III, Fig 2). These results probably reflect the normal caudal widening of the lumbar spine and spinal canal.

The IALS dimensions found in the late radiographs were usually similar to those found in the earlier films taken 10 years before $(p>0.05)$. The mean values of the IALS height $(\mathrm{H}), \mathrm{H} / \mathrm{W}$ and $\mathrm{H} / \mathrm{V}$, showed a constant decrease with time. The difference between the mean values of $\mathrm{H}$ and $\mathrm{H} / \mathrm{V}$ in the late and early examinations increased from L1 down to L5 (Table IV, Fig 3). This difference, however, was significant only below the L5 vertebrae $(p<0.05)$. The subjective evaluation of the $\mathrm{x}$-ray films of the lumbar spine revealed few abnormali-

Table II The width index (WI) and ratio between IALS height (H) and width (W)

\begin{tabular}{lccccc}
\hline & $\begin{array}{c}\text { L1 } \\
\text { Mean } \pm \text { SD } \\
(\mathrm{mm})\end{array}$ & $\begin{array}{c}\text { Mean } \pm \text { SD } \\
(\mathrm{mm})\end{array}$ & $\begin{array}{c}\text { Mean } \pm \text { SD } \\
(\mathrm{mm})\end{array}$ & $\begin{array}{c}\text { Mean } \pm \text { SD } \\
(\mathrm{mm})\end{array}$ & $\begin{array}{c}\text { Mean } \pm \text { SD } \\
(\mathrm{mm})\end{array}$ \\
\hline WI-A & $0.37 \pm 0.06$ & $0.38 \pm 0.07$ & $0.45 \pm 0.10$ & $0.50 \pm 0.10$ & $0.60 \pm 0.11$ \\
WI-B & $0.38 \pm 0.09$ & $0.40 \pm 0.08$ & $0.46 \pm 0.10$ & $0.49 \pm 0.09$ & $0.60 \pm 0.10$ \\
H/W-A & $0.75 \pm 0.17$ & $0.81 \pm 0.15$ & $0.69 \pm 0.17$ & $0.59 \pm 0.17$ & $0.50 \pm 0.15$ \\
H/W-B & $0.71 \pm 0.17$ & $0.75 \pm 0.16$ & $0.65 \pm 0.14$ & $0.58 \pm 0.20$ & $0.47 \pm 0.16$ \\
\hline
\end{tabular}

A. Early radiographs. B. Late radiographs. 
Table III Mean IALS dimensions, width of overlying vertebrae and ratios between them

\begin{tabular}{lcccccc}
\hline & $\begin{array}{c}\text { L1 } \\
\text { Mean } \pm \text { SD } \\
(\mathrm{mm})\end{array}$ & $\begin{array}{c}\text { L2 } \\
\text { Mean } \pm \text { SD } \\
(\mathrm{mm})\end{array}$ & $\begin{array}{c}\text { L3 } \\
\text { Mean } \pm \text { SD } \\
(\mathrm{mm})\end{array}$ & $\begin{array}{c}\text { L4 } \\
\text { Mean } \pm \text { SD } \\
(\mathrm{mm})\end{array}$ & $\begin{array}{c}\text { L5 } \\
\text { Mean } \pm \text { SD } \\
(\mathrm{mm})\end{array}$ \\
\hline $\mathrm{H}$ & $\mathrm{A}$ & $14.5 \pm 2.76$ & $16.2 \pm 2.33$ & $16.5 \pm 3.73$ & $15.4 \pm 3.32$ & $16.1 \pm 4.21$ \\
$\mathrm{H}$ & $\mathrm{B}$ & $14.5 \pm 3.34$ & $16.0 \pm 2.57$ & $16.1 \pm 2.87$ & $14.6 \pm 3.05$ & $15.1 \pm 4.53$ \\
$\mathrm{~W}$ & $\mathrm{~A}$ & $19.8 \pm 2.61$ & $20.5 \pm 3.13$ & $24.3 \pm 4.34$ & $27.1 \pm 4.50$ & $32.6 \pm 5.15$ \\
$\mathrm{~W}$ & $\mathrm{~B}$ & $20.8 \pm 4.97$ & $21.8 \pm 3.88$ & $25.3 \pm 4.56$ & $26.6 \pm 4.80$ & $33.1 \pm 5.24$ \\
$\mathrm{~V}$ & $\mathrm{~A}$ & $51.1 \pm 6.33$ & $51.7 \pm 4.83$ & $54.5 \pm 4.73$ & $58.5 \pm 5.27$ & $64.8 \pm 6.39$ \\
$\mathrm{~V}$ & $\mathrm{~B}$ & $50.8 \pm 4.42$ & $51.9 \pm 3.15$ & $54.9 \pm 3.00$ & $58.1 \pm 3.53$ & $65.1 \pm 5.66$ \\
$\mathrm{H} / \mathrm{V}$ & $\mathrm{A}$ & $0.29 \pm 0.07$ & $0.32 \pm 0.06$ & $0.31 \pm 0.08$ & $0.27 \pm 0.07$ & $0.25 \pm 0.07$ \\
$\mathrm{H} / \mathrm{V}$ & $\mathrm{B}$ & $0.29 \pm 0.07$ & $0.31 \pm 0.05$ & $0.29 \pm 0.06$ & $0.25 \pm 0.05$ & $0.23 \pm 0.07$ \\
W/V A & $0.39 \pm 0.07$ & $0.40 \pm 0.07$ & $0.45 \pm 0.10$ & $0.47 \pm 0.08$ & $0.51 \pm 0.09$ \\
W/V & B & $0.41 \pm 0.10$ & $0.42 \pm 0.07$ & $0.46 \pm 0.10$ & $0.46 \pm 0.09$ & $0.51 \pm 0.09$ \\
\hline
\end{tabular}

$\mathrm{H}=$ IALS height, $\mathrm{W}=$ maximal IALS width, $\mathrm{V}=$ width of overlying vertebra. A. Early radiographs. B. Late radiographs.

Table IV Differences between late and early mean IALS height $(\Delta \mathrm{H})$, IALS width $(\Delta \mathrm{W})$, width of overlying vertebrae $(\Delta \mathrm{V})$, ratio between IALS height and vertebral width $(\Delta \mathrm{H} / \mathrm{V})$ and ratio between IALS width and vertebral width $(\Delta \mathrm{W} / \mathrm{V})$

\begin{tabular}{lrrrrr}
\hline & $\begin{array}{c}\mathrm{L} 1 \\
(\mathrm{~mm})\end{array}$ & $\begin{array}{c}\mathrm{L} 2 \\
(\mathrm{~mm})\end{array}$ & $\begin{array}{c}\mathrm{L} 3 \\
(\mathrm{~mm})\end{array}$ & $\begin{array}{c}\mathrm{L} 4 \\
(\mathrm{~mm})\end{array}$ & $\begin{array}{c}\mathrm{L} 5 \\
(\mathrm{~mm})\end{array}$ \\
\hline$\Delta \mathrm{H}$ & 0.08 & 0.19 & 0.46 & 0.77 & 1.00 \\
$\Delta \mathrm{W}$ & -1.08 & -1.38 & -1.00 & 0.54 & -0.46 \\
$\Delta \mathrm{V}$ & 0.38 & -0.23 & -0.38 & 0.31 & -0.31 \\
$\Delta \mathrm{H} / \mathrm{V}$ & 0.00 & 0.01 & 0.01 & 0.01 & 0.02 \\
$\Delta \mathrm{W} / \mathrm{V}$ & 0.02 & -0.02 & -0.01 & 0.01 & 0.00 \\
\hline
\end{tabular}

ties. The IALS morphology looked unchanged on the 10 year follow up films. In one patient (no 2) osteophytes extended laterally from the L4-L5 vertebral bodies. In another patient (no 6) L2-L3 and L4-L5 osteophyte extension and L4-L5 intervertebral space narrowing were noticed. Additional findings were L5 sacralisation (no 2) and S1 spina bifida (no 7).

\section{Discussion}

Changes in the lumbar spine dimensions reflect the normal process of aging. ${ }^{1}$ One would expect that alteration in the forces exerted on the spine as a consequence of paresis would lead to additional vertebral changes by remodelling and osteoarthritis. This is, however, the first study investigating the effect of paraparesis on the shape

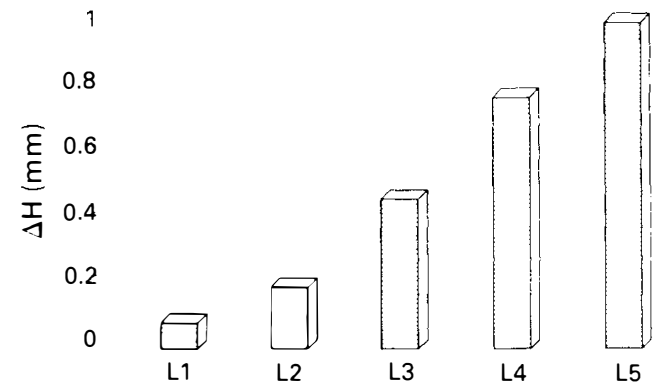

Figure 3 Differences between mean IALS height below lumbar vertebrae on early and late radiographs $(\Delta \mathrm{H}), \Delta \mathrm{H}$ increases from $\mathrm{L} 1$ down to L5 level, but becomes significant only below L5 vertebra $(p<0.05)$.

and dimensions of the lumbar spine, to the best of our knowledge.

Our findings indicate that paraparesis does not induce significant changes in the lumbar vertebrae. In contrast to our expectations, the IALS dimensions of the paraparetic patients changed only slightly during the follow up period. The narrowing of the vertebral canal and the horizontal widening of the vertebral bodies characterising aging ${ }^{1}$ were not observed in our patients. This may be explained by the relative immobilisation of the patients with spinal lesions, which might slow the degenerative or remodelling processes. Since not only pathological changes but also the normal aging process changes were usually absent in our patients, it seems that paraparesis may even prevent 
some expected spinal bone changes. It could be argued that 10 years is a rather short period for aging phenomena to occur. Pathological spine changes, however, should have been apparent within the follow up period.

The increase in the differences between the mean height values from the L1 to the L5 IALS in the late and the early radiographs may indicate that age dependent changes in the spinal dimensions are more prominent caudally (Fig 3 ). Below the L5 vertebra, the IALS height was significantly reduced within 10 years. This reduction may represent hypertrophy of the laminae at this level, but it may also represent a narrowing of the L5-S1 intervertebral disc space. Unfortunately, this space was ill defined on the examined AP films, and its height could not be measured for comparison with the IALS height.

Various methods have been presented in the literature for assessing the dimensions of the spinal canal. It has been customary to consider the interpedicular distance or the interfacet distance as the width of the canal. The values of these indices vary among normal populations of various ethnic groups ${ }^{6,7}$ but always increase from the L1 down to the L5 level. The IALS maximum width mean values found in this study were within the range of values of the inter- pedicular distance of previous studies ${ }^{7-10}$ and also increased from L1 to L5 (Table III). Thus, the maximum IALS width is probably an equally suitable index of the lumbar spinal canal width. The midsagittal AP diameter has been employed as a predictor of central spinal stenosis and was found to correlate with the cross-sectional area of the spinal canal or dural sac in computerised tomographic and anatomic studies. ${ }^{10,11}$ Consequently, the midsagittal AP diameter is probably the best radiological index of clinically significant canal stenosis. Measurement of the IALS and vertebral body width on the AP radiographs, followed by subjective evaluation of the films, is superior, however, for detection of long term spinal changes. The method enables assessment of the dimensions and shape of both posterior and anterior elements of the lumbar spine with routine follow up examinations. The use of ratios between dimensions, and not absolute values, eliminates errors of measurement induced by different magnifications.

As only few significant changes were found in the AP radiographs of the lumbar vertebrae within a 10 year follow up period, we conclude that paraparesis does not accelerate the aging process of the lumbar spine, and relative immobilisation may even retard it.

\section{References}

1 Twomey L, Taylor J (1988) Age changes in the lumbar spinal and intervertebral canals. Paraplegia 26: 238-239.

2 Twomey L, Taylor J (1983) Sagittal movements of the human lumbar vertebral column: a quantitative study of the role of the posterior vertebral elements. Arch Phys Med Rehabil 64: 322-325.

3 Twomey L, Taylor J (1986) Age changes in lumbar zygapophyseal joints: observations on structure and function. Spine 11: 739-745.

4 Wylie EJ, Chakera TMH (1988) Degenerative joint abnormalities in patients with paraplegia of duration greater than 20 years. Paraplegia 26: 101-106.

5 Vouge M (1980) Interapophysolaminar spaces (IALS) of the lumbar spine and their utility in the diagnosis of narrow lumbar canal. In: Wackenheim A, Babin E, editors. The Narrow Lumbar Canal. Springer-Verlag, Berlin: 23-25.

6 Eisenstein S (1977) The morphometry and pathological anatomy of the lumbar spine in South African Negroes and Caucasoids with specific reference to spinal stenosis. J Bone Joint Surg 59B: 173-180.

7 Amonoo-Kuofi HS, Patel PJ, Fatani AJ (1990) Transverse diameter of the lumbar spinal canal in normal adult Saudis. Acta Anat 137: 124-128.

8 Vanharanta H, Korpi J, Heliovaara M, Troup JDG (1985) Radiographic measurements of lumbar spinal canal size and their relation to back mobility. Spine 10: 461-465.

9 Kornberg M, Rechtine GR (1985) Quantitative assessment of the fifth lumbar spinal canal by computed tomography in symptomatic L4-L5 disc disease. Spine 10: 328-330.

10 Schonstrom NSR, Bolender NF, Spengler DM (1985) The pathomorphology of spinal stenosis as seen on CT scans of the lumbar spine. Spine 10: 806-811.

11 Gepstein R, Folman Y, Sagiv P, Ben David Y, Hallel T (1991) Does the auteroposterior diameter of the spinal canal reflect its size? An anatomical study. Surg Anat Radiol 13: 289-291. 